\title{
Penerapan Arsitektur Regionalisme pada Tampilan Bangunan Balai Latihan KerJa Kabupaten Sleman
}

\author{
Shalila Ariesta, Sumaryoto, Tri Joko Daryanto \\ Program Studi Arsitektur \\ Fakultas Teknik \\ Universitas Sebelas Maret \\ Email: $\underline{\text { shalila_ariesta@student.uns.ac.id }}$
}

\begin{abstract}
Economic globalization and trade, affect the qualification requirements and the types of labor are higher. Data from ministry of labor showed the competitiveness and productivity of labor in Indonesia relatively more low due to the low level of workforce education. Employment or Training Institute Training Center (BLK) is owned by Government Institutions, aims for the labor gets a chance to adding or sharpen work skills. The conditions of BLK Sleman previously still under minimum standards, whereas the interest and term of trainees are high enough. Redesign of exsisting building, making the BLK Sleman more optimal as the means and infrastructure to transform knowledge, skills and productive working, to improve the quality and competitiveness of Indonesian manpower. The design problem is to redesign BLK Sleman with architectural regionalism on the look of the building. The purpose of the redesign is to eksistence maintained of the training institute building and reflects the identity of the region. The design method used relate the architecturof the past and contemporary architecture by selecting one of the characteristics of traditional building details that are well known on the public. The result of the design can optimize and utilize the functions of BLK will be a credible, acceptable, and Independently institute through a system repair, methods, programs, facilities, and infrastructure with attention to the linkages between old building with new building.
\end{abstract}

Keywords: Architectural Regionalism, Building Look, , Labor, Redesign, Sleman District, Training Center

\section{PENDAHULUAN}

Lembaga Pelatihan Kerja atau Balai Latihan Kerja (BLK) adalah salah satu instrumen milik pemerintah guna menghasilkan tenaga kerja yang kompeten. Di BLK, tenaga kerja mendapat kesempatan untuk menambah keterampilan atau mengasah keterampilan kerja.

Redesain Balai Latihan Kerja Kabupaten Sleman dianggap penting, dikarenakan pemberdayaan Balai Latihan Kerja (BLK) belum optimal. Padahal datadari Lemsar.net menunjukkan bahwa animo dan jumlah peserta pelatihan di BLK Kabupaten Sleman tertinggi kedua setelah BLKPP Kota Yogyakarta. Di BLK Kabupaten Sleman masih ditemukan beberapa kekurangan dan fasilitas yang tersedia masih di bawah standar minimal .(Depnakertrans. 2007)
Arsitektur Regionalisme dipilih sebagai penekanan redesain pada tampilan bangunan Balai Latihan Kerja Kabupaten Sleman agar bangunan memiliki ciri khas dan identitas daerah. Pada bangunan eksisting aspek konstekstual sudah ditemukan melalui atap joglo pada bagian hall sebagai simbol pendopo, namun masih kurang dalam memunculkan identitas daerah. Balai Latihan Kerja Kabupaten Sleman dirancang ulang sebagai salah satu penanganan untuk mengoptimalkan dan mendayagunakan fungsi dengan memperhatikan keterkaitan antara bangunan lama dengan bangunan baru, serta menerapkan arsitektur regionalisme dalam tampilan bangunan, agar dapat meningkatkan eksistensi lembaga pelatihan melalui bangunan yang mencerminkan identitas daerah. 


\section{METODE}

Perancangan ulang Balai Latihan Kerja bermula dari pemikiran untuk menciptakan suatu wadah kegiatan pelatihan keterampilan yang juga bermanfaat bagi ekonomi maupun industri. Redesain melalui proses evaluasi purna huni terhadap bangunan berdasarkan aspek pada matriks jenis evaluasi (Snyder \& Catanese, 1989). Perancangan tersebut juga mempertimbangkan konsep pembangunan yang memperhatikan prinsipprinsip arsitektur regionalisme, di mana fungsi bangunan sangat berhubungan dengan teknologi dan mesin namun tampilan bangunan tetap kontekstual dengan lingkungan sekitar.

Strategi desain yang akan terapkan pada Balai Latihan Kerja Kabupaten Sleman berpedoman pada konsep analogi, hakekat identifikasi tempat, bangunan atau sesuatu yang mempunyai karakteristik menonjol sesuai dengan masalah rancangan.

Prinsip Arsitektur Regionalisme yang diterapkan pada desain antara lain adalah (Wondoamiseno, 1991):

1. Perilaku manusia sebagai titik tolak merancang, landasan utama agar hasil rancangan bermanfaat bagi manusia sendiri. Penyatuan budaya lama dan budaya baru.

2. Mengkaitkan AML (Arsitektur Masa Lampau) dan AMK (Arsitektur Masa kini) dengan cara merancang sesuai karakteristik. Mengulang karakteristikelemen-elemen lama diungkapkan pada elemen-elemen baru.

3. Mengkaitkan AML (Arsitektur Masa Lampau) dan AMK (Arsitektur Masa kini) dengan memilih ciri salah satu detail bangunan tradisional yang telah dikenal oleh masyarakat.

4. Mengkaitkan AML (Arsitektur Masa Lampau) dan AMK (Arsitektur Masa kini) dengan mengambil beberapa karakter detail tradisional diungkapkan kembali dengan skala dan material berbeda tetapi masih menunjukan ekspresi tradisional.

\section{ANALISIS}

\subsection{Analisis Peruangan}

\subsubsection{Tujuan}

Mengetahui jenis ruang, besaran ruang, identitas ruang, serta pola peletakan ruang yang dibutuhkan.

\subsubsection{Dasar Pertimbangan}

1. Kegiatan pelaku dan jenis kegiatan yang disesuaikan dengan kebutuhan dari kegiatan berdasarkan data-data yang dilakukan melalui pengamatan langsung ke lapangan.

2. Kriteria ruang sebagai tolak ukur sasaran kenyamanan ruang.

3. Kegiatan yang diwadahi, sifat kegiatan, fungsi kegiatan, hubungan antar kegiatan, dan pencapaian.

Berikut menunjukan kegiatan dan kebutuhan ruang:

Tabel 1. Kebutuhan Ruang

\begin{tabular}{|c|l|l|}
\hline No. & Kegiata & Kebutuhan Ruang \\
\hline 1 & $\begin{array}{l}\text { Semua } \\
\text { Pengguna }\end{array}$ & $\begin{array}{l}\text { Lapangan, Aula, } \\
\text { Parkir, Kantin, } \\
\text { Musholla }\end{array}$ \\
\hline 2 & Penerima & Hall \\
\hline 3 & Pengelola & $\begin{array}{l}\text { R. Kantor, Loket } \\
\text { Pendaftaran }\end{array}$ \\
\hline 4 & Pelatihan & $\begin{array}{l}\text { Perpustakaan, R. } \\
\text { Teori, R. } \\
\text { Workshop }\end{array}$ \\
\hline 5 & Servis & $\begin{array}{l}\text { Gudang, Pantry, } \\
\text { R.Peralatan } \\
\text { Kebersihan, Pos } \\
\text { Jaga }\end{array}$ \\
\hline 6 & Penunjang & $\begin{array}{l}\text { Rumah Dinas, } \\
\text { Asrama }\end{array}$ \\
\hline
\end{tabular}

\subsection{Analisis Lokasi}

\subsubsection{Tujuan}

Mengetahui kondisi lingkungan tapak yang telah menjadi lokasi BLK Kabupaten Sleman sebelumnya.

\subsubsection{Dasar Pertimbangan \\ 3.2.2.1 Potensi}

1. Tapak berupa lahan kosong untuk diadakan pengembangan pembangunan secara vertikal maupun horizontal.

2. Lokasi tapak berada di pinggir jalan raya jalur alternatif Yogyakarta - Magelang via Turi dan jalur alternatif Jalan Kaliurang. 
3. Lokasi berada didaerah tidak padat penduduk, sehingga proses pelatihan tidak terlalu berdampak mengganggu lingkungan sekitar.

4. Lokasi berdekatan denga sarana dan prasarana kesehatan yaitu RSUD Sleman guna pertolongan lanjut kecelakaan pada pelatihan.

\subsubsection{Kendala}

1. Lokasi tapak tidak berada dekat kawasan pemerintahan Sleman.

2. Terdapat angkutan umum yang melewati jalan depan BLK Kabupaten Sleman, namun memiliki intensitas melintas yang sangat lama.

3. Jalan raya depan BLK Kabupaten Sleman terbilang cukup sepi lalu lintas dibanding jalan sebelahnya yaitu Jalan Kaliurang. Sehingga keberadaan BLK Kabupaten Sleman kurang diketahui masyarakat luas.

\subsubsection{Batas-batas Tapak}

Utara: Jalan Srowolan

Selatan: Lahan Kosong

Barat: Sawah dan Sungai

Timur: Jalan Palagan Tentara Pelajar

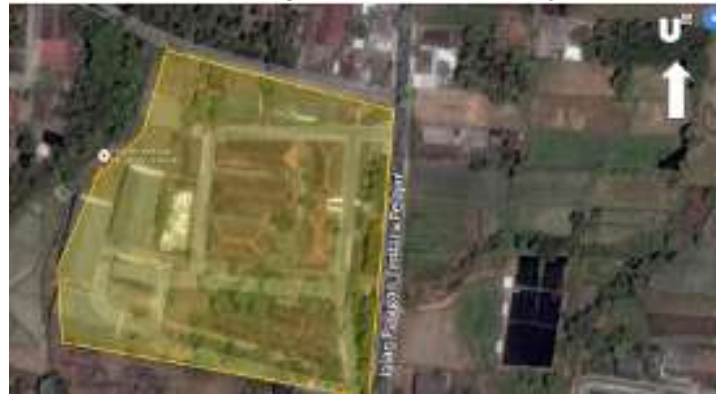

Gambar 1. Lokasi Tapak

Gambar1. Menunjukan lokasi dan foto udara massa bangunan bangunan BLK Kabupaten Sleman sebelumnya.

\subsection{Analisis Pencapaian \\ 3.3.1 Tujuan}

Mendapatkan pola pencapaian yaitu berupa main entrance dan side entrance.

\subsubsection{Dasar Pertimbangan}

1. Main entrance diletakkan di jalan utama sesuai dengan kondisi semula, sedangkan side entrance ditambahkan di sisi jalan yang berbeda.
2. Kemudahan pencapaian bagi kendaraan pribadi dari jalan utama maupun kemudahan pencapaian bagi kendaraan umum dan pejalan kaki untuk mencapai site.

3. Sirkulasi main entrance (in and out) dan side entrance tidak menyebabkan kemaceten lalu lintas.

4. Menyesuaikan dengan arah pergerakan lalu lintas kendaraan pada jalan yang mengelilingi site.

Main entrance berbatasan dengan $\mathrm{Jl}$. Palagan Tentara Pelajar dan side entrance berada pada sisi utara tapak. Perbatasan dengan Jl. Srowolan. Jalan Palagan Tentara merupakan jalur utama, sedangkan side entrance berbatasan dengan Jl. Srowolan. Posisi side entrance berbeda dengan main entrance. Bertujuan untuk memudahkan sirkulasi pengguna kegiatan lain agar tidak mengganggu kegiatan utama.

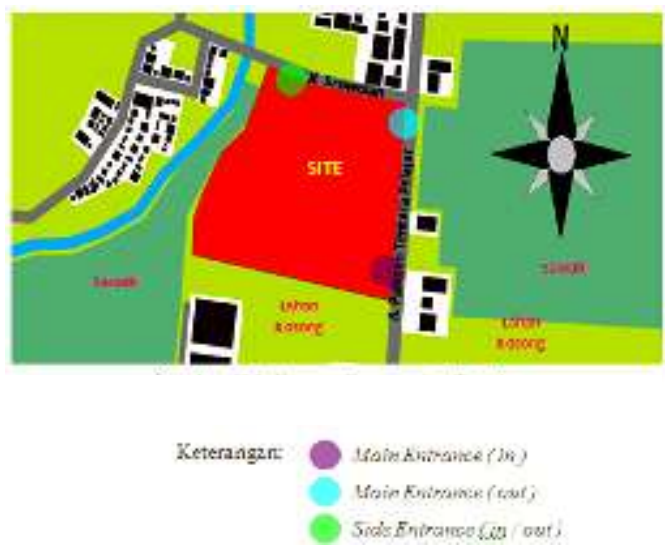

Gambar 2. Hasil Analisa Pencapaian

Gambar 2. Main entrance berada pada sisi timur tapak, yang berbatasan dengan $\mathrm{Jl}$. Palagan Tentara Pelajar. Side entrance berada pada sisi utara tapak yang berbatasan dengan Jl. Srowolan. Jalan Palagan Tentara merupakan jalur utama, sehingga memudahkan pengunjung menemukan akses masuk.

\subsection{Analisis Pandangan dan Orientasi 3.4.1 Tujuan}

Mengetahui potensi - potensi objek pandang yang maksimal pada lokasi tapak. Potensi pandangan berpengaruh pada orientasi bangunan. Sehingga analisis orientasi 
bertujuan untuk menentukan arah bangunan serta pengelompokkan zona pada tapak berdasarkan kebutuhan pandangan pada setiap ruang.

\subsubsection{Dasar Pertimbangan}

1. Kondisi eksisting sekitar tapak

2. Potensi view yang maksimal

3. Letak terhadap pencapaian tapak

Orientasi bangunan ke arah poin-poin potensial pandangan menuju tapak. Pengoptimalan fasad berada di orientasi bangunan pada arah main entrance dan side entrance.

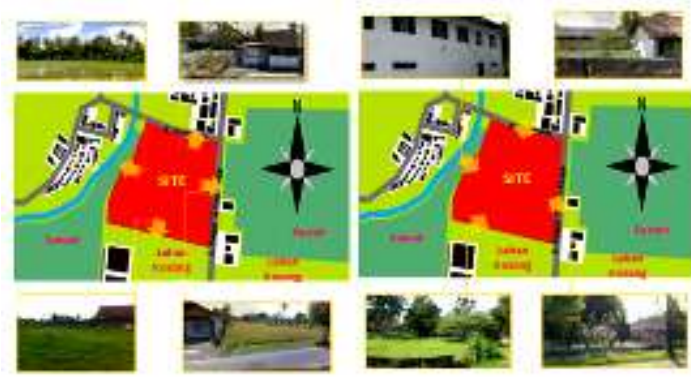

Gambar 3. Pandangan dari dan menuju tapak.

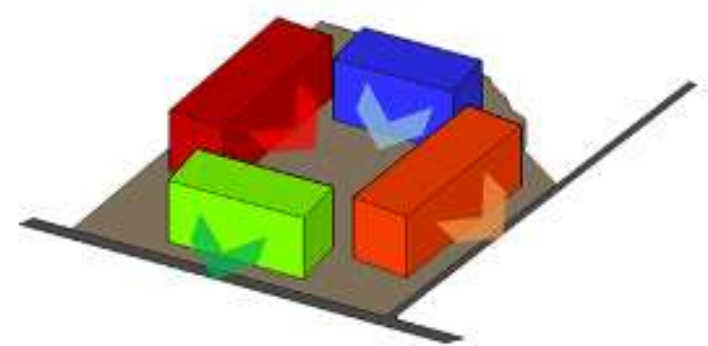

Gambar 4. Hasil Analisa Pandangan dan Orientasi.

Gambar 4. menunjukan orientasi utama bangunan menghadap ke timur tapak yaitu Jl. Palagan Tentara Pelajar dan persawahan. Pada bagian tersebut dijadikan fasad utama yang harus dirancang maksimal. Orientasi kedua bangunan menghadap ke utara tapak yaitu Jl. Srowolan dan rumah warga. Pada bagian tersebut dijadikan fasad kedua yang harus dirancang menarik. Berdasarkan analisis pandangan ke utara kurang maksimal, maka dinding tertutup di ganti dengan pagar dan vegetasi yang cukup membatasi pandangan dari tapak menuju rumah warga. Pada sisi yang menghadap Selatan dan Barat tidak berpotensi untuk diadakan orientasi bangunan keluar tapak, maka orientasi akan diarahkan ke dalam.

\subsection{Analisis Pemintakatan (zoning) \\ 3.5.1 Dasar Pertimbangan}

1. Jenis pengelompokan kegiatan

2. Pencapaian tapak.

3. Pandangan dan orientasi

Pemintakatan berdasarkan kelompok kegiatan dan analisis pengolahan tapak.

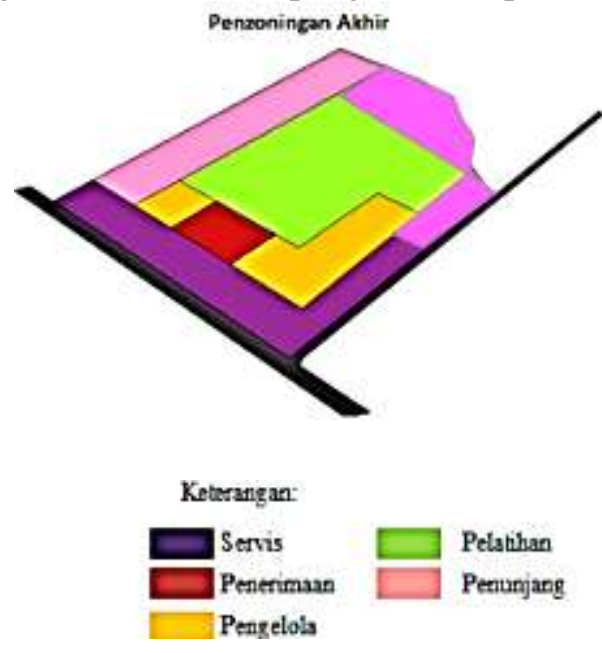

Gambar 5. Hasil Pemintakatan Tapak.

\subsection{Analisis Bentuk dan Tata Massa}

\subsubsection{Tujuan}

Menentukan bentuk bangunan guna menciptakan ruang-ruang efisien dan optimal, yang mendukung fungsi pelatihan. Bentuk massa di tata berdasarkan pertimbangan kelancaran dan keefektifan kawasan antar zona massa sehingga memudahkan pencapaian dalam pola sirkulasi, yang sesuai kondisi tapak.

\subsubsection{Dasar Pertimbangan}

\subsubsection{Bentuk Massa}

1. Fungsi bangunan

2. Standar dimensi ruang yang ditentukan

3. Penzoningan kelompok kegiatan pada analisis tapak

\subsubsection{Tata Massa}

1. Hubungan aktivitas dan fungsi kegiatan

2. Penempatan main entrance dan side entrance

3. Tata massa dan pola sirkulasi bangunan lama 
Dari sifat dan karakter massa dasar, terpilih bentuk massa bujur sangkar karena dinilai paling sesuai dengan fungsi yang mewadahi kegiatan. Hal yang diutamakan adalah optimalisasi ruang sebagai tempat pelatihan dan kantor pengelola.

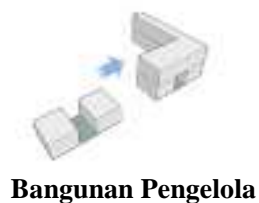

Bangunan Pengelola

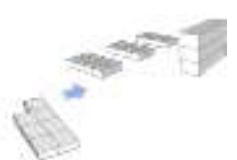

Bangunan Penunjang

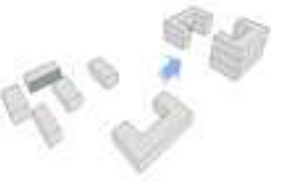

Bangunan Pelatihan

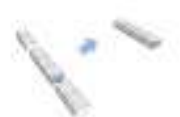

Bangunan Servis
Gambar 6. Hasil Bentuk Massa Bangunan.

Bangunan dengan kegiatan yang memiliki hubungan diletakkan berdekatan. Akses sikulasi kendaraan dapat menjangkau seluruh bangunan memudahkan kegiatan servis. . Alur sirkulasi bangunan lama yang dipertahankan juga disesuaikan dengan hasil analisis pencapaian dikarenakan tambahan side entrance. Perbaikan pengelolaan zona parker adalah menyediakan satu titik lahan parkir untuk seluruh kendaraan, guna meminimalisir polusi udara dan polusi suara.

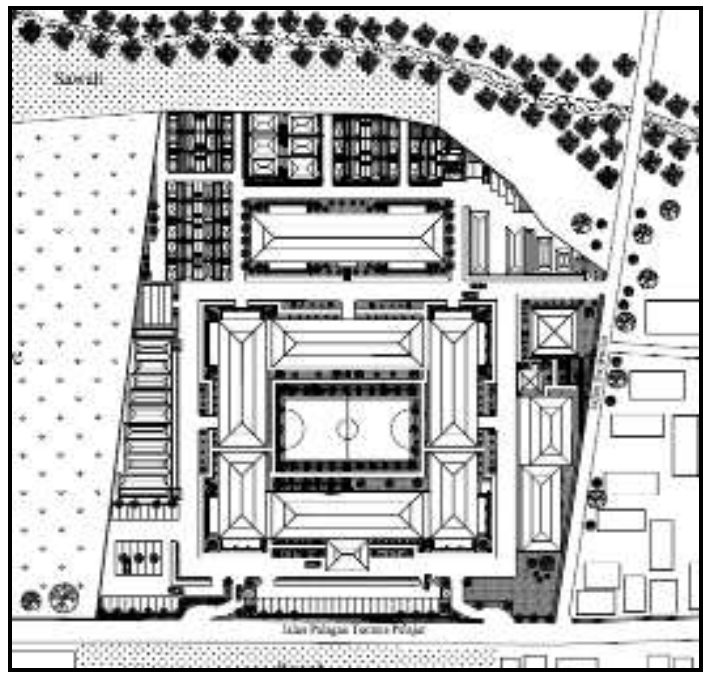

Gambar 7. Hasil Tata Massa Bangunan

\subsection{Analisis Tampilan Bangunan}

\subsubsection{Tujuan}

Menentukan tampilan baru dengan mempertimbangkan prinsip-prinsip penekanan. Tampilan bangunan mencirikan identitas daerahnya,serta meningkatkan citra dan eksistensi bangunan, namun tetap sesuai dengan fungsi.

\subsubsection{Dasar Pertimbangan}

1. Prinsip arsitektur regionalisme yang akan diterapkan

2. Hasil pengolahan tapak

3. Karakter kegiatan yang akan diwadahi

Prinsip arsitektur regionalisme yang dijadikan pedoman utama adalah mengkaitkan arsitektur masa lampau dan arsitektur masa kini dengan memilih ciri salah satu detail bangunan tradisional yang telah dikenal oleh masyarakat. Berdasarkan konsep analogi dan hakekat identifikasi tempat dalam arsitektur regionalism maka arsitektur masa lampau atau arsitektur tradisional yang dipilih adalah Arsitektur Jawa. Spesifikasi pada atap joglo dengan mengambil salah satu ciri detail bangunan tradisional yang telah dikenal baik oleh masyarakat, yaitu struktur rongrongan tumpang sari. (Dakung, 1983)

\subsubsection{Interior}

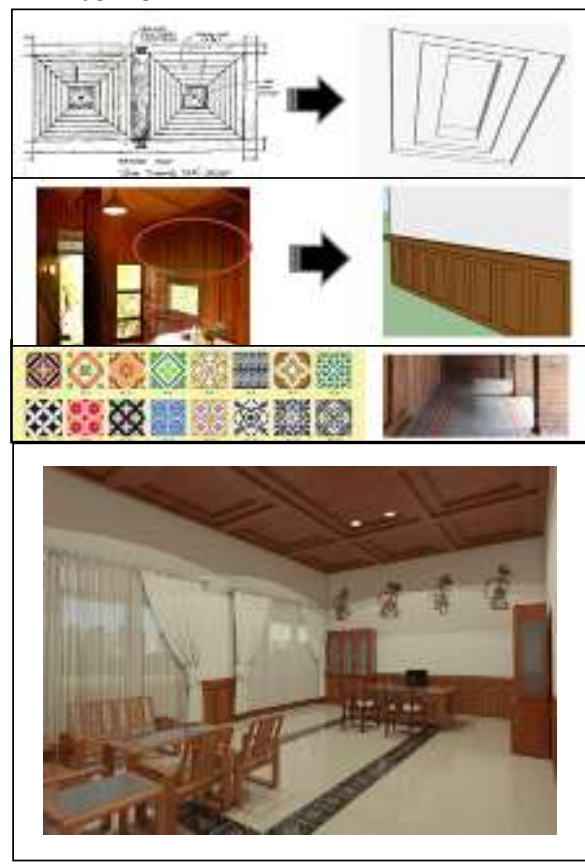

Gambar 8. Hasil Tampilan Interior

\subsubsection{Eksterior}




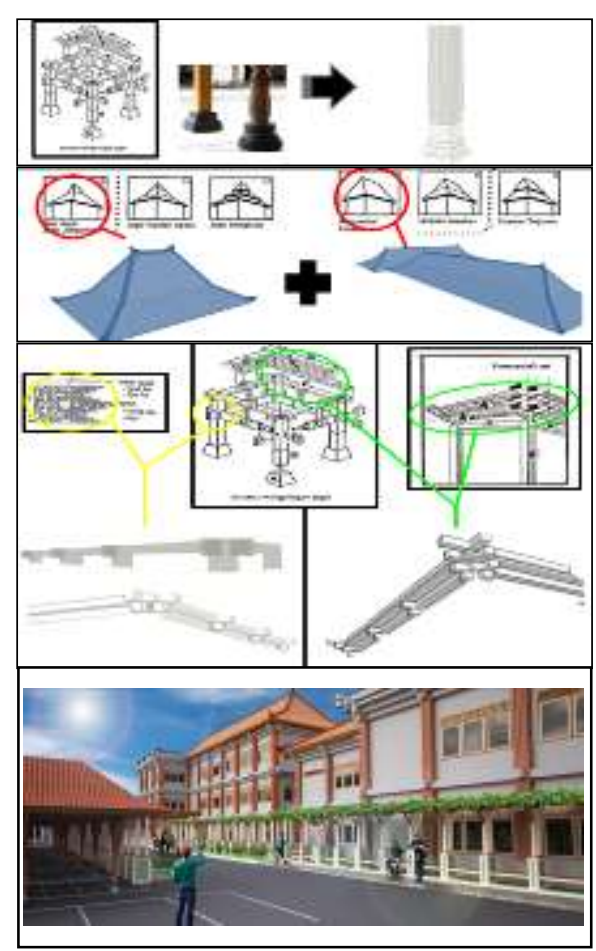

Gambar 9. Hasil Tampilan Eksterior

\section{KESIMPULAN (KONSEP DESAIN)}

Konsep rancangan Balai Latihan Kerja kabupaten Sleman mengacu pada konsep pengguna, kegiatan, ruang, sirkulasi dan penekanan Arsitektur Regionalisme Struktur Joglo pada tampilan bangunan. Dari hasil analisis serta korelasi dari data di atas, maka diperoleh hasil berupa rancangan Balai Latihan Kerja Kabupaten Sleman, Redesain dengan Penekanan Arsitektur Regionalisme pada Tampilan Bangunan sebagai berikut:

Nama Bangunan: Balai Latihan Kerja Kabupaten Sleman

Lokasi : Jalan Palagan Tentara Pelajar Km. 15, Bunder, Purwobinangun, Pakem, Sleman, Yogyakarta

Luas Lahan : $17.000 \mathrm{~m} 2$

Luas Bangunan : $20.090 \mathrm{~m} 2$

Daya Tampung : 1.500 orang

Kegiatan : Pelatihan Kerja/Ketrampilan

Arsitektur Regionalisme ditekankan pada aspek bentuk dan tampilan bangunan.. Hasil akhir adalah lingkungan pelatihan kerja atau ketrampilan, dengan sarana dan prasarana yang memadai serta fasilitas penunjang yang diadakan sesuai kebutuhan .

Berikut adalah beberapa ilustrasi bentuk penerapan Arsitektur Regionalisme pada tampilan bangunan.

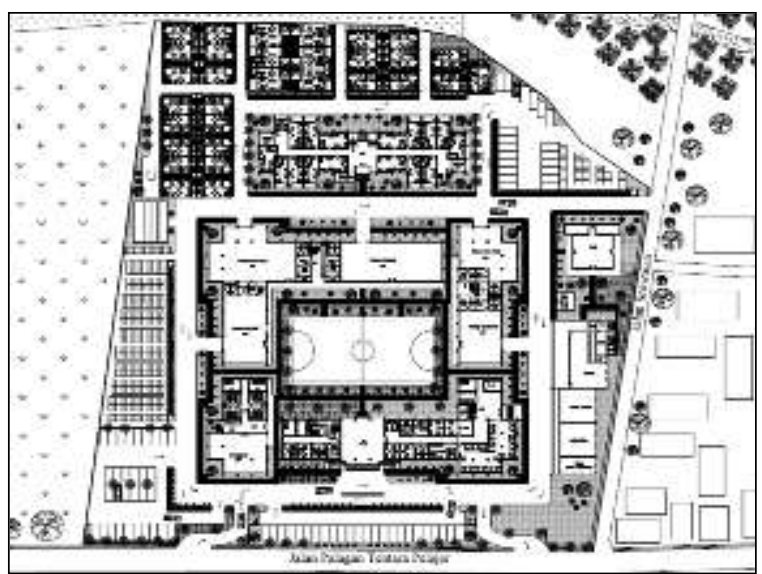

Gambar 10. Siteplan

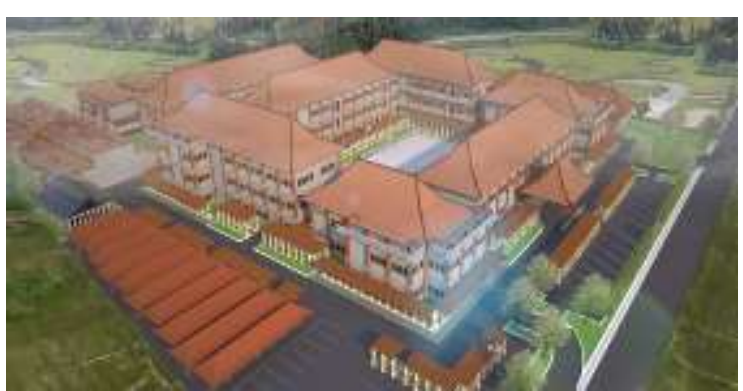

Gambar 11. Foto Udara Kawasan

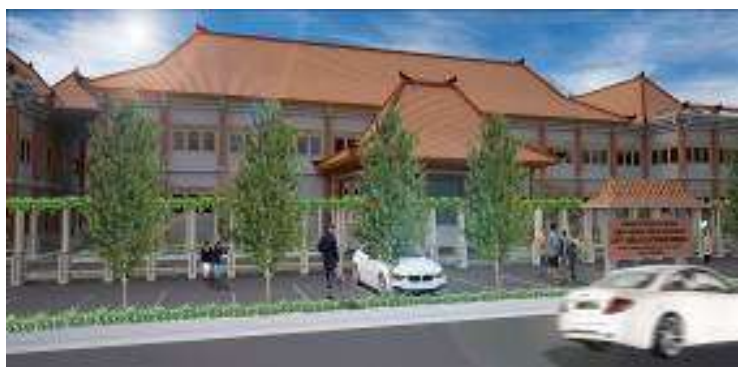

Gambar 12. Tampak depan.

\section{REFERENSI}

Dakung,

Tradisional Daerah Istimewa

Yogyakarta. Jakarta: Depdikbud Pusat.

Depnakertrans. 2007. Standar Minimum BLK. Jakarta: Direktorat Jendral Pembinaan Pelatihan dan Produktivitas.

Snyder, James C.\& Catanese, Anthony J. 1989. Pengantar Arsitektur. Jakarta: Erlangga.

Wondoamiseno, R.A. 1991. Regionalisme dalam Arsitektur Indonesia : Sebuah Harapan. Yogyakarta: Yayasan Rupadatu 